\title{
Comparative Analysis of the Antioxidant Activity of Cassia fistula Extracts
}

\author{
Md. Irshad, ${ }^{1,2,3}$ Md. Zafaryab, ${ }^{1}$ Man Singh, ${ }^{2}$ and M. Moshahid A. Rizvi ${ }^{1}$ \\ ${ }^{1}$ Department of Biosciences, Jamia Millia Islamia, New Delhi 110025, India \\ ${ }^{2}$ School of Chemical Sciences, Central University of Gujarat, Gujarat, Gandhinagar 382030, India \\ ${ }^{3}$ Department of Medical Education, College of Medicine, King Saud University, Riyadh 11321, Saudi Arabia
}

Correspondence should be addressed to M. Moshahid A. Rizvi, rizvijmi@gmail.com

Received 24 May 2012; Revised 27 August 2012; Accepted 27 August 2012

Academic Editor: Hussein El-Subbagh

Copyright (๑) 2012 Md. Irshad et al. This is an open access article distributed under the Creative Commons Attribution License, which permits unrestricted use, distribution, and reproduction in any medium, provided the original work is properly cited.

\begin{abstract}
Antioxidant potential of various extracts of Cassia fistula was determined by the DPPH, FRAP, $\mathrm{Fe}^{3+}$ reducing power, and hydrogen peroxide scavenging assay. Methanolic extracts of Cassia fistula showed the highest amount of phenolic and flavonoid content and reducing capacity, whereas hexane extracts exhibited the lowest level of reducing capacity. The order of antioxidant activity in Cassia fistula extracts displayed from higher to lower level as methanolic extracts of pulp, methanolic extracts of seed, hexane extracts of pulp, and hexane extracts of seed. The antioxidant potential of Cassia fistula extracts significantly correlated $(P<0.02)$ with the phenolic content of the methanolic extracts. Ascorbic acid taken as control showed highest antioxidant power in the present study.
\end{abstract}

\section{Introduction}

Cassia fistula Linn. (Caesalpiniaceae) has great therapeutic implication in Indian system of medicine and exerts an antipyretic, analgesic, antiinflammatory, and hypoglycemic effects $[1,2]$. Over the past few years, there has been an exponential growth in study of pharmacological properties of this plant [3-5]. Antioxidant components are microconstituents that inhibit lipid oxidation by inhibiting the initiation or propagation of oxidizing chain reactions, and are also involved in scavenging of free radicals. Clinical approaches of antioxidants increased multifold during the recent time for the management and therapeutic implication of neurodegenerative disorders, aging, and chronic degenerative diseases. In view of the above, we designed the study to evaluate the antioxidant potential and phenolic content in Cassia fistula.

\section{Materials and Methods}

2.1. Reagent and Chemicals. All the chemicals and solvents were of analytical grade and obtained from Merck and HiMedia, Mumbai, India.
2.2. Preparation of Cassia fistula Extracts. The fresh ripe fruits of Cassia fistula were collected in June from the campus of Delhi College of Pharmaceutical Science and Research (DIPSAR), New Delhi, India, and properly authenticated. A voucher of specimen (PM 21) was stored in the laboratory for further reference. The fruit pulp and seed were separated and grounded to coarse powder. It was extracted with the hexane for $72 \mathrm{hrs}$ and the same materials were reextracted with methanol for $72 \mathrm{hrs}$ in soxhlet apparatus. The extract was filtered and dried in rotavapour. Hence, we obtained hexane extract of seed (HES), hexane extract of pulp (HEP), methanolic extract of seed (MES), and methanolic extract of pulp (MEP).

2.3. Estimation of Total Phenolic Content. The total phenol content was estimated in the methanolic extracts of seed and pulp using Folin-Ciocalteu reagent (FCR) according to the procedure reported by Singleton et al. [6], using standard Gallic acid $\left(Y=1.8478 x+0.0702, R^{2}=0.9971\right)$ and Tannic acid $\left(Y=1.388 x+0.0472, R^{2}=0.9958\right)$, curve standardized in the lab for the calculation of Gallic acid equivalent (GAE) and Tannic acid equivalent (TAE) per gram of extracts, respectively. The blue complex was 
formed by the reduction of reagent by phenolic compounds in extract. Briefly, aliquot of $400 \mu \mathrm{L}$ of extract was added to $1.6 \mathrm{~mL}$ of sodium carbonate $(7.5 \%$ in deionised water) and $2 \mathrm{~mL}$ of Folin-Ciocalteu reagent (diluted 10-fold in deionised water). After incubation of $1 \mathrm{hr}$ at room temperature, absorbance was measured at $525 \mathrm{~nm}$ using LaboMed Inc. Spectrophotometer (USA). All determination was carried out in triplicate. Total phenolic content was expressed in mg GAE and TAE per gram of extracts, using calibration curve.

2.4. Estimation of Flavonoid Content. Total flavonoids contents were estimated both in methanolic extracts of pulp and seed by method of Zhishen et al. [7], using Quercetin standard. Briefly, $0.5 \mathrm{~mL}$ of aliquot of extract was added to $75 \mu \mathrm{L}$ of $5 \% \mathrm{NaNO}_{2}$ solution. After 6 minutes, $150 \mu \mathrm{L}$ of a $10 \% \mathrm{AlCl}_{3} 6 \mathrm{H}_{2} \mathrm{O}$ solution was added and the mixture was allowed to stand another 5 minutes. Then, $0.5 \mathrm{~mL}$ of $1 \mathrm{~mol} / 1$ $\mathrm{NaOH}$ and $2.5 \mathrm{~mL}$ of distilled water was added. The solutions were mixed and absorbance was measured at $510 \mathrm{~nm}$ using LaboMed Inc. Spectrophotometer (USA). All experiments were carried out in triplicate. Total flavonoid content was calculated as $\mathrm{mgQE} / \mathrm{g}$, using the following equation based on the calibration curve:

$$
Y=2.234 x+0.992, \quad R^{2}=0.9927,
$$

where $x$ was the absorbance and $y$ was the $\mathrm{mgQE} / \mathrm{g}$.

2.5. DPPH Radicals Scavenging Activity. DPPH radicals scavenging of Cassia fistula extracts was estimated according to the method of Miliauskas $[8,9]$. DPPH radicals absorbed maximum at $515 \mathrm{~nm}$, which disappears with reduction by an antioxidant compound (s). Three milliliter (3 mL) DPPH solution in methanol $(0.1 \mathrm{mM})$ was mixed with $100 \mu \mathrm{L}$ of extracts $(\mathrm{mg} / \mathrm{mL})$. In control $100 \mu \mathrm{L}$ methanol (without extracts) mixed with DPPH solution. The samples were incubated in a water bath for $20 \mathrm{~min}$ at $37^{\circ} \mathrm{C}$, and the decrease in absorbance at $515 \mathrm{~nm}$ was measured. Ascorbic acid was used as positive reference. The experiment was carried out in triplicate. Radical scavenging activity was calculated using the following formula:

$$
\% \text { inhibition }=\left[\frac{(\mathrm{AC}-\mathrm{AE})}{\mathrm{AB}}\right] \times 100,
$$

where $\mathrm{AC}=$ absorbance of the control and $\mathrm{AE}=$ absorbance of tested samples.

2.6. Ferric Reducing Antioxidant Potential (FRAP) Assay. Ferric reducing power of Cassia fistula extracts were determined using FRAP assay $[10,11]$. This method is based on the reduction of colourless ferric complex $\left(\mathrm{Fe}^{3+}\right.$ tripyridyltriazine) to blue-colored ferrous complex $\left(\mathrm{Fe}^{2+}\right.$ tripyridyltriazine) by the action of electron donating antioxidants at low $\mathrm{pH}$. The reduction was monitored by measuring the change of absorbance at $593 \mathrm{~nm}$. The working FRAP reagent was prepared by mixing 10 volumes of $300 \mathrm{mM}$ acetate buffer, $\mathrm{pH}$ 3.6, with 1 volume of $10 \mathrm{mM}$ TPTZ (2,4,6-tri(2-pyridyl)-striazine) in $40 \mathrm{mM} \mathrm{HCl}$ and with 1 volume of $20 \mathrm{mM}$ ferric chloride. All the required solutions were freshly prepared before their uses. $100 \mu \mathrm{L}$ of samples $(\mathrm{mg} / \mathrm{mL})$ were added to $3 \mathrm{~mL}$ of prepared FRAP reagent. The reaction mixture was incubated in a water bath for $30 \mathrm{~min}$ at $37^{\circ} \mathrm{C}$. Then, the absorbance of the samples was measured at $593 \mathrm{~nm}$. The difference between absorbance of sample and the absorbance of blank was calculated and used to calculate the FRAP value. FRAP value was expressed in terms of $\mathrm{mmol} \mathrm{Fe} \mathrm{F}^{2+} / \mathrm{g}$ of sample using ferric chloride standard curve $Y=1.7057 x-$ $0.2211, R^{2}=0.9904$. All measurements were calculated from the value obtained from triplicate assays.

2.7. Hydroxyl Radical Scavenging Activity Assay. The scavenging activity for hydroxyl radicals was measured with Fenton reaction $[12,13]$. Reaction mixture contained $60 \mu \mathrm{L}$ of $1.0 \mathrm{mM} \mathrm{FeCl}, 90 \mu \mathrm{L}$ of $1 \mathrm{mM} \mathrm{1,10-phenanthroline,}$ $2.4 \mathrm{~mL}$ of $0.2 \mathrm{M}$ phosphate buffer ( $\mathrm{pH} 7.8$ ), $150 \mu \mathrm{L}$ of $0.17 \mathrm{M}$ $\mathrm{H}_{2} \mathrm{O}_{2}$, and $1.5 \mathrm{~mL}$ of extract at various concentrations. After incubation at room temperature for $5 \mathrm{~min}$, the absorbance of reaction mixture was noted at $560 \mathrm{~nm}$. The hydroxyl radicals scavenging activity was calculated according to the following equation and compared with ascorbic acid as standard:

$$
\% \text { Inhibition }=\left(\frac{(\mathrm{AB}-\mathrm{AE})}{\mathrm{AB}} \times 100\right),
$$

where $\mathrm{AB}$ was the absorbance of blank (without extract) and $\mathrm{AE}$ was the absorbance of tested samples.

2.8. Reducing Power Assay. The $\mathrm{Fe}^{3+}$ reducing power of extracts was determined by the method of Oyaizu [9, 11, 14]. The extract $(0.75 \mathrm{~mL})$ of various concentrations was mixed with $0.75 \mathrm{~mL}$ of phosphate buffer $(0.2 \mathrm{M}, \mathrm{pH} 6.6)$ and $0.75 \mathrm{~mL}$ of potassium hexacyanoferrate $\left(\mathrm{K}_{3} \mathrm{Fe}(\mathrm{CN})_{6}\right)$ $(1 \%, \mathrm{w} / \mathrm{v})$, followed by incubation at $50^{\circ} \mathrm{C}$ in a water bath for $20 \mathrm{~min}$. The reaction was stopped by adding $0.75 \mathrm{~mL}$ of trichloroacetic acid (TCA) solution (10\%) and mixture centrifuged at $800 \mathrm{~g}$ for $10 \mathrm{~min} .1 .5 \mathrm{~mL}$ of the obtained supernatant was mixed with $1.5 \mathrm{~mL}$ of distilled water and $0.1 \mathrm{~mL}$ of ferric chloride $\left(\mathrm{FeCl}_{3}\right)$ solution $(0.1 \%, \mathrm{w} / \mathrm{v})$ for $10 \mathrm{~min}$. The absorbance of reaction mixture was taken at $700 \mathrm{~nm}$. Higher value absorbance of the reaction mixture indicated greater reducing power.

\section{Statistical Analysis}

Results were expressed as mean value $\pm \mathrm{SD}(n=3)$. Regression analysis was performed to calculate the doseresponse relation between the extracts. Linear regression analysis was performed to find out the correlation coefficient. Statistical significance was evaluated employing $t$-test and $P<0.05$ which were considered to be significant.

\section{Result and Discussion}

4.1. DPPH Radical Scavenging. DPPH (1,1-diphenyl-2picrylhydrazyl) analysis is one of the best-known, accurate, and frequently employed methods for evaluating antioxidant activity [15]. It is a stable free radical because of its 


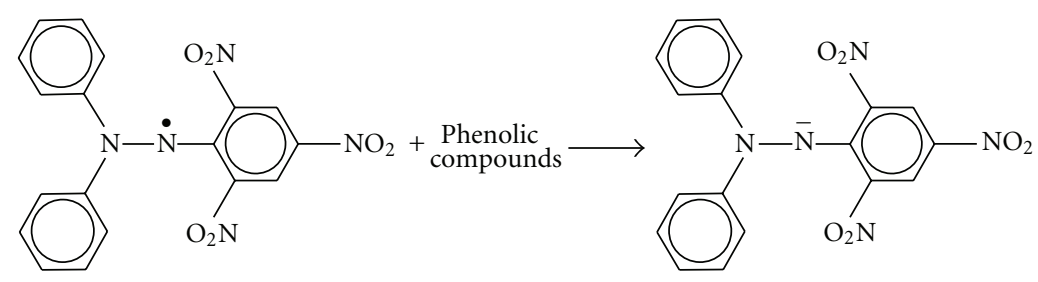

DPPH free radical

DPPH reduced form

SCHeme 1

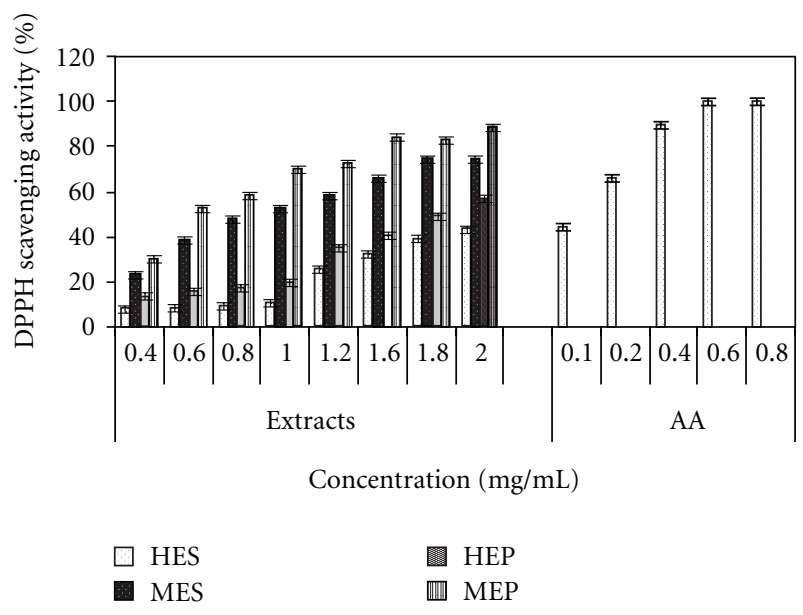

FIGURE 1: The graphical representation of DPPH scavenging activity of hexane extracts of seed (HES), pulp (HEP), methanolic extracts of seed (MES), and pulp (MEP). Values are expressed as mean \pm standard deviation $(n=3)$. Ascorbic acid (AA) was used as a standard.

spare electron delocalization over the whole molecule. The donation of $\mathrm{H}^{+}$to the DPPH radicals made a corresponding change from violet colour to pale yellow in the solution. The DPPH scavenging also made a proportionate decrease in its absorbance at $517 \mathrm{~nm}$ (see Scheme 1).

The order of DPPH scavenging against Cassia fistula extract was found to be in the order of MEP > MES > HEP > HES. Antioxidant activity of the methanol extracts of pulp and seed was also compared to total phenolic content and it was further found that radical scavenging effects of extracts were directly proportional to the phenolic content present in extracts (Table 1). Hence, methanol extract of pulp and seed showed the significant radical scavenging as the concentration increased, whereas hexane extract of pulp and seed showed low scavenging effect up to $1 \mathrm{mg} / \mathrm{mL}$; thereafter, DPPH scavenging increased with the concentration of extract. The positive control, ascorbic acid showed maximum scavenging effect at very low concentration (Figure 1). A significant correlation coefficient ( $r, 0.978$ ) was found between the antioxidant activity of the methanolic extract of pulp and seed. The proton radical scavenging action is known to be one of the important mechanisms for measuring antioxidant activity. This assay determines the scavenging of stable
TABLE 1: Quantification of total phenolic and flavonoid contents in methanolic extract of pulp (MEP) and seed (MES).

\begin{tabular}{|c|c|c|c|}
\hline \multirow{2}{*}{ Cassia fistula extracts } & \multicolumn{2}{|c|}{ Total phenolic } & \multirow{2}{*}{ Flavonoids** } \\
\hline & Quercetine* $^{*}$ & Tannic acid ${ }^{* *}$ & \\
\hline MEP & $114.23 \pm 1.05$ & $107 \pm 0.87$ & $74.65 \pm 1.12$ \\
\hline MES & $109 \pm 1.05$ & $96 \pm 1.08$ & $67.78 \pm 0.98$ \\
\hline
\end{tabular}

* Total phenolic contents ( $\mathrm{mg}$ gallic acid equivalent/g).

** Total phenolic contents ( $\mathrm{mg}$ tannic acid equivalent/g).

$* * *$ Flavonoid (mg quercetin equivalent/g).

radical species $D P P H$ by antioxidants compounds present in the extracts. The results showed the greater rate of DPPH scavenging activity of both the methanolic extracts as compared to thehexane extracts probably due to the presence of high content of phenolic compounds. $\mathrm{EC}_{50}$ value was determined from the plotted graph of scavenging activity against various concentrations of extracts, which is defined as the efficient concentration of antioxidant necessary to decrease the initial DPPH radicals concentration by $50 \%$ (Table 2). The lowest $\mathrm{EC}_{50}$ indicates the strongest ability of the extracts to act as DPPH radicals scavengers. Out of the all extracts, methanolic extract of pulp and seed showed the lowest $\mathrm{EC}_{50}, 0.915$ and $1.088 \mathrm{mg} / \mathrm{mL}$, whereas hexane extracts of pulp and seed showed 1.865 and $2.239 \mathrm{mg} / \mathrm{mL}$, respectively (Table 2). Ascorbic acid showed highest DPPH radicals scavenging with $\mathrm{EC}_{50}$ of $0.102 \mathrm{mg} / \mathrm{mL}$. Sun and Ho reported a significant correlation between total phenolics and scavenging ability of buckwheat extracts on DPPH radicals [16]. Our study clearly indicated that the methanol extracts of pulp and seed of Cassia fistula exhibited high content of phenolic compounds which was significantly correlated with the DPPH radical scavenging activity $(P<$ $0.005)$.

4.2. Hydroxyl Radical Scavenging Activity. The hydroxyl radicals are extremely reactive oxygen species that can react with every possible molecule in living organisms, especially with proteins, DNA, and lipids [17]. Hydroxyl radicals are capable of rapid initiation of the lipid peroxidation process by extracting hydrogen atoms from unsaturated fatty acids [18]. The electron or proton donation capacities of Cassia fistula extracts were further confirmed by the Fenton reaction system. Under in vitro, condition very reactive $\mathrm{OH}^{-}$radicals were formed through the Fenton reaction. The reversible reaction between $\mathrm{Fe}^{2+}$ and 1,10-Phenathroline 
TABLE 2: $\mathrm{EC}_{50}$ value is defined as the effective concentration of antioxidant necessary to decrease the radical concentration by $50 \%$. FRAP values represent as equivalent mmol of $\mathrm{Fe}^{2+}$ /gram sample.

\begin{tabular}{lccc}
\hline $\begin{array}{l}\text { Cassia fistula } \\
\text { extracts }\end{array}$ & $\begin{array}{c}\mathrm{EC}_{50}(\mathrm{DPPH}) \\
\mathrm{mg} / \mathrm{mL}\end{array}$ & $\begin{array}{c}\mathrm{EC}_{50} \text { (hydroxyl peroxide) } \\
\mathrm{mg} / \mathrm{mL}\end{array}$ & $\begin{array}{c}\text { FRAP } \\
\text { value }\end{array}$ \\
\hline MEP & 0.915 & 0.889 & 136.05 \\
MES & 1.088 & 1.058 & 112.02 \\
HEP & 1.865 & 1.723 & 75.09 \\
HES & 2.239 & 2.075 & 69.02 \\
Ascorbic acid & 0.102 & 0.105 & - \\
\hline
\end{tabular}

formed $\mathrm{Fe}$ (phen $)_{2}{ }^{2+}$, which react with $\mathrm{H}_{2} \mathrm{O}_{2}$ and formed $\mathrm{OH}^{-}$free radicals $[19,20]$ :

$$
\begin{aligned}
& \mathrm{Fe}(\text { phen })_{3}^{2+} \leftrightarrows \mathrm{Fe}(\text { phen })_{2}^{2+}+\text { phen, } \\
& \mathrm{Fe}(\text { phen })_{2}^{2+}+\mathrm{H}_{2} \mathrm{O}_{2} \longrightarrow \mathrm{Fe}(\text { phen })_{2}^{3+}+\mathrm{OH}^{-}+{ }^{\bullet} \mathrm{OH}
\end{aligned}
$$

Among the reactive oxygen species (ROs), $\mathrm{H}_{2} \mathrm{O}_{2}$ is the most reactive and predominant radical generating molecule endogenously during aerobic metabolism [21]. The results showed that methanolic extracts of pulp and seed of Cassia fistula have scavenging ability of $\mathrm{OH}^{-}$free radicals in a dosedependent manner (Figure 2). The highest activity was noted for the pulp extract of methanol followed by methanolic extract of seed at all concentrations. $\mathrm{OH}^{-}$free radical scavenging potential of all the extracts was found to be lower than that of the reference compound ascorbic acid. The $\mathrm{EC}_{50}$ values of MEP, MES, HES, HEP, and ascorbic acid were $0.889,1.058,2.075,1.723$, and $0.105 \mathrm{mg} / \mathrm{mL}$, respectively (Table 2). The trend obtained in $\mathrm{OH}^{-}$free radical scavenging behaviour was similar to the DPPH free radical scavenging nature (Figure 2). The result of $\mathrm{OH}^{-}$free radical scavenging activity was significantly correlated with the DPPH free radical scavenging $(P, 0.05)$.

4.3. Reducing Power. The reducing power assay is often used to evaluate the ability of an antioxidant to donate an electron [22]. In this assay, the ability of extracts to reduce $\mathrm{Fe}^{3+}$ to $\mathrm{Fe}^{2+}$ was determined. The presence of antioxidants in the extracts resulted into reduction of the ferric cyanide complex $\left(\mathrm{Fe}^{3+}\right)$ to the ferrous cyanide form $\left(\mathrm{Fe}^{2+}\right)$. In reducing power assay, antioxidants cause the reduction of the $\mathrm{Fe}^{3+}$ into $\mathrm{Fe}^{2+}$, thereby changing the solution into various shades from green to blue, depending on the reducing power of the compounds [23]. Strong reducing agents, however, formed Perl's Prussian blue colour and absorbed at $700 \mathrm{~nm}$. Figure 3 showed the reducing activities of various extracts of Cassia fistula in comparison with ascorbic acid as standard. The higher the absorbance of the reaction mixture, the higher would be the reducing power. Methanolic extract of pulp and seed showed some degree of electron donation. Reducing power of different extracts increased with the concentration of the extract. Hexane extract of seed and pulp showed less degree of $\mathrm{Fe}^{3+}$ reduction than the methanolic extracts. The reducing power was found to be in order of MEP > MES > HEP > HES. Interestingly, the rate of

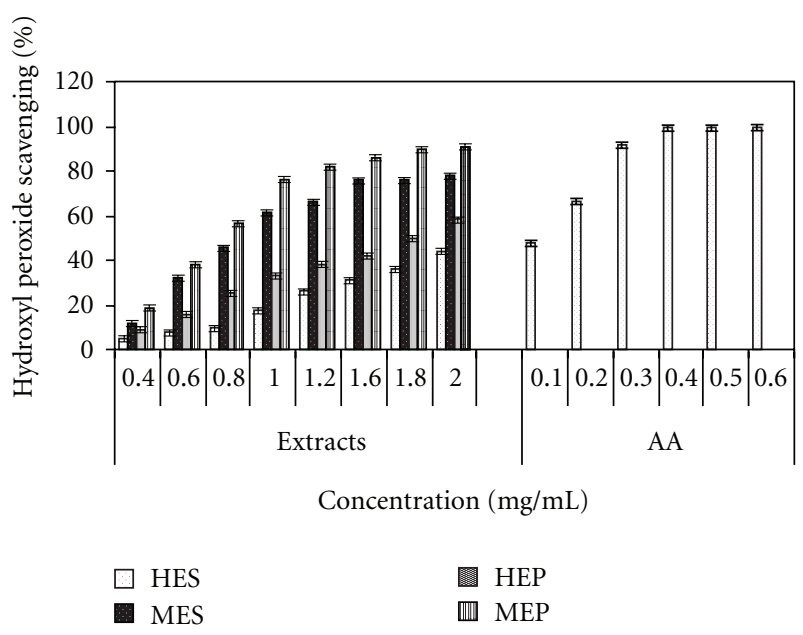

FIgure 2: The graphical representation of hydroxyl radical scavenging activity of hexane extracts of seed (HES), pulp (HEP), methanolic extracts of seed (MES), and pulp (MEP). Values are expressed as mean \pm standard deviation $(n=3)$. Ascorbic acid (AA) was used as a standard.

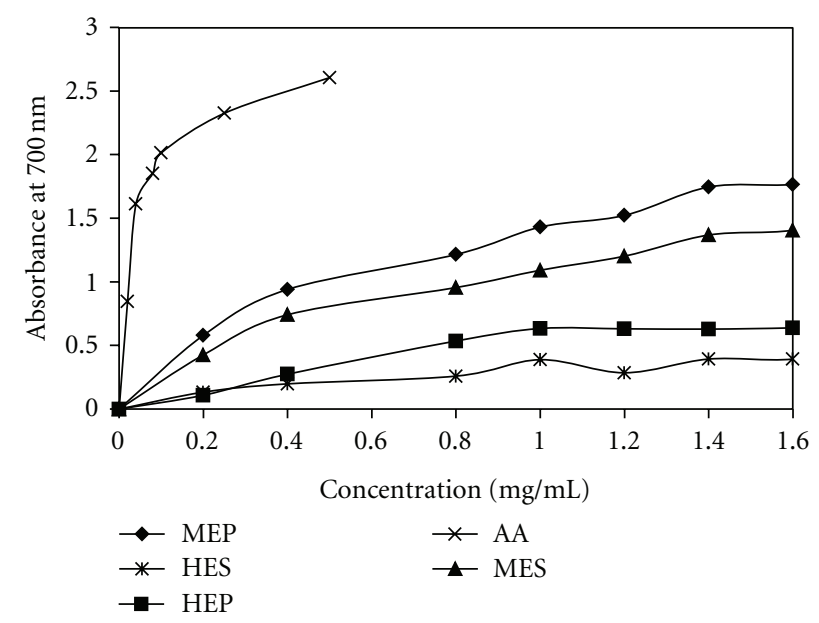

FIGURE 3: The graphical representation of reducing power of hexane extracts of seed (HES), pulp (HEP), methanolic extracts of seed (MES), and pulp (MEP). Values are expressed as mean \pm standard deviation $(n=3)$. Ascorbic acid (AA) was used as a standard.

reducing power of methanolic extracts of both pulp and seed (MEP and MES) first increased rapidly with concentration but later it decreased. The reducing power of reference compound (Ascorbic acid) was found to be higher than all the tested extracts. It has been reported that the reducing power of substances is probably because of their hydrogendonating ability [24]. Methanolic extracts of pulp and seed might, therefore, contain high amount of reductones than hexane extracts of pulp and seed. Hence, methanolic extracts of fruit pulp and seed may act as electron donors and could react with free radicals to convert them into more stable products and then terminate the free radical chain reactions. 
Bhalodia et al. [25] recently reported antioxidant activity of the Cassia fistula flower. They reported that the hydroalcoholic extract of flower demonstrated significant radical scavenging activity in ferric reducing power and DPPH assays. It was also correlated with the total phenols which could be responsible for the antioxidant activity [25].

The reducing power assay is often used to evaluate the ability of an antioxidant to donate an electron which is an important mechanism of phenolic antioxidant action [17]. Many reports have revealed that there is a direct correlation between antioxidant activities and reducing power of certain plant extracts [26, 27].

4.4. FRAP Assay. FRAP assay measures the reducing potential of an antioxidant reacting with a ferric tripyridyltriazine $\left(\mathrm{Fe}^{3+}\right.$-TPTZ) complex and producing a coloured ferrous tripyridyltriazine ( $\left.\mathrm{Fe}^{2+}-\mathrm{TPTZ}\right)$ [28]. The reducing properties associated with the presence of compounds exert their action by breaking the free radical chain through donating a hydrogen atom [29, 30]. FRAP assay showed positive correlation between reducing power and phenolic content in Cassia fistula extracts (Table 2). Here also, methanolic extracts of pulp showed greater FRAP value as 136.05 equivalent mmol of $\mathrm{Fe}^{2+} / \mathrm{g}$ sample. The other extracts MES, HEP, and HES showed FRAP value 112.02, 75.09, and 69.02 equivalent mmol of $\mathrm{Fe}^{2+} / \mathrm{g}$ samples, respectively. The result was similar with Benzie and Szeto [27], who found a strong correlation between total phenolic content and FRAP assay. Rice-Evans et al. [30] reported that phenolic compounds have redox properties, which allow them to act as reducing agents, hydrogen donators, and singlet oxygen quenchers. The redox potential of phenolic compounds played an important role in determining the antioxidant potential.

\section{Conclusion}

Antioxidant potential of Cassia fistula extract demonstrated the highest reducing power in the methanolic extract of pulp and seed. It was concluded that the antioxidant activity of these extracts was directly proportional to the phenolic contents. The hexane extracts of seed and pulp, however, did not significantly reduce the free radicals under in vitro study.

\section{Acknowledgment}

The authors acknowledge Professor M. P. Sharma (Department of Botany, Jamia Hamdard, New Delhi, India) for the identification of plant materials.

\section{References}

[1] D. G. Patel, S. S. Karbhari, O. D. Gulati, and S. D. Gokhale, "Antipyretic and analgesic activities of Aconitum spicatum and Cassia fistula," Pharmaceutical Biology, vol. 157, no. 1, pp. 2227, 1965.

[2] M. M. A. Rizvi, M. Irshad, G. El Hassadi, and S. B. Younis, "Bioefficacies of Cassia fistula: an Indian labrum," African Journal of Pharmacy and Pharmacology, vol. 3, no. 6, pp. 287292, 2009.
[3] T. Bhakta, P. K. Mukherjee, K. Mukherjee, M. Pal, and B. P. Saha, "Studies on in vivo wound healing activity of Cassia fistula linn. Leaves (Leguminosae) in rats," Natural Product Sciences, vol. 4, no. 2, pp. 84-87, 1998.

[4] M. Irshad, M. Singh, and M. M. A. Rizvi, "Assessment of anthelmintic activity of Cassia fistula L," Middle East Journal of Science and Research, vol. 5, pp. 346-349, 2010.

[5] M. Irshad, S. Shreaz, N. Manzoor, L. A. Khan, and M. M. A. Rizvi, "Anticandidal activity of Cassia fistula and its effect on ergosterol biosynthesis," Pharmaceutical Biology, vol. 49, no. 7, pp. 727-733, 2011.

[6] V. L. Singleton, R. Orthofer, and R. M. Lamuela-Raventós, "Analysis of total phenols and other oxidation substrates and antioxidants by means of folin-ciocalteu reagent," Methods in Enzymology, vol. 299, pp. 152-178, 1998.

[7] J. Zhishen, T. Mengcheng, and W. Jianming, "The determination of flavonoid contents in mulberry and their scavenging effects on superoxide radicals," Food Chemistry, vol. 64, no. 4, pp. 555-559, 1999.

[8] G. Miliauskas, P. R. Venskutonis, and T. A. Van Beek, "Screening of radical scavenging activity of some medicinal and aromatic plant extracts," Food Chemistry, vol. 85, no. 2, pp. 231-237, 2004.

[9] W. Boonchum, Y. Peerapornpisal, D. Kanjanapothi et al., "Antioxidant activity of some seaweed from the Gulf of Thailand," International Journal of Agriculture and Biology, vol. 13, no. 1, pp. 95-99, 2011.

[10] S. Dudonné, X. Vitrac, P. Coutiére, M. Woillez, and J. M. Mérillon, "Comparative study of antioxidant properties and total phenolic content of 30 plant extracts of industrial interest using DPPH, ABTS, FRAP, SOD, and ORAC assays," Journal of Agricultural and Food Chemistry, vol. 57, no. 5, pp. 1768-1774, 2009.

[11] S. Luqman, S. Srivastava, R. Kumar, A. K. Maurya, and D. Chanda, "Experimental assessment of Moringa oleifera leaf and fruit for its antistress, antioxidant, and scavenging potential using in vitro and in vivo assays," Evidence-Based Complementary and Alternative Medicine, vol. 2012, Article ID 519084, 2012.

[12] L. Yu, S. Haley, J. Perret, M. Harris, J. Wilson, and M. Qian, "Free radical scavenging properties of wheat extracts," Journal of Agricultural and Food Chemistry, vol. 50, no. 6, pp. 16191624, 2002.

[13] G. P. Ganu, S. S. Jadhav, and A. D. Deshpande, "Antioxidant and antihyperglycemic potential of methanolic extract of bark of mimusops elengi 1. In mice," International Journal of Phytomedicine, vol. 2, no. 2, pp. 116-123, 2010.

[14] M. Oyaizu, "Studies on products of browning reactions: antioxidant activities of products of browning reaction prepared from glucose amine," Japanese Journal of Nutrition, vol. 44, pp. 307-315, 1986.

[15] K. Zhou and L. Yu, "Effects of extraction solvent on wheat bran antioxidant activity estimation," LWT_Food Science and Technology, vol. 37, no. 7, pp. 717-721, 2004.

[16] T. Sun and C. T. Ho, "Antioxidant activities of buckwheat extracts," Food Chemistry, vol. 90, no. 4, pp. 743-749, 2005.

[17] H. Mohamed, M. Ons, E. T. Yosra, S. Rayda, G. Neji, and N. Moncef, "Chemical composition and antioxidant and radicalscavenging activities of Periploca laevigata root bark extracts," Journal of the Science of Food and Agriculture, vol. 89, no. 5, pp. 897-905, 2009.

[18] O. I. Aruoma, "Free radicals, oxidative stress, and antioxidants in human health and disease," Journal of the American Oil Chemists' Society, vol. 75, no. 2, pp. 199-212, 1998. 
[19] J. Burgess and R. H. Prince, "1132. Kinetics of reactions of ligand-substituted tris-(2,2' - bipyridyl)iron(II) complexes," Journal of the Chemical Society, pp. 6061-6066, 1965.

[20] M. Cyfert, "Kinetics of reaction of $\mathrm{Fe}(\text { phen })_{3}^{2+}$ with hydrogen peroxide in neutral medium," Inorganica Chimica Acta, vol. 98, no. 1, pp. 25-28, 1985.

[21] C. Walling, "Fenton's reagent revisited," Accounts of Chemical Research, vol. 8, no. 4, pp. 125-131, 1975.

[22] A. Yildirim, A. Mavi, M. Oktay, A. A. Kara, O. F. Algur, and V. Bilaloglu, "Comparison of antioxidant and antimicrobial activities of Tilia (Tilia argentea Desf ex DC), sage (Salvia triloba L.), and Black tea (Camellia sinensis) extracts," Journal of Agricultural and Food Chemistry, vol. 48, no. 10, pp. 50305034, 2000.

[23] I. C. F. R. Ferreira, P. Baptista, M. Vilas-Boas, and L. Barros, "Free-radical scavenging capacity and reducing power of wild edible mushrooms from northeast Portugal: individual cap and stipe activity," Food Chemistry, vol. 100, no. 4, pp. 15111516, 2007.

[24] K. Shimada, K. Fujikawa, K. Yahara, and T. Nakamura, "Antioxidative properties of xanthan on the autoxidation of soybean oil in cyclodextrin emulsion," Journal of Agricultural and Food Chemistry, vol. 40, no. 6, pp. 945-948, 1992.

[25] N. R. Bhalodia, P. B. Nariya, R. N. Acharya, and V. J. Shukla, "Evaluation of in vitro antioxidant activity of flowers of Cassia fistula Linn," International Journal of PharmTech Research, vol. 3, pp. 589-599, 2011.

[26] I. I. Koleva, T. A. Van Beek, J. P. H. Linssen, A. De Groot, and L. N. Evstatieva, "Screening of plant extracts for antioxidant activity: a comparative study on three testing methods," Phytochemical Analysis, vol. 13, no. 1, pp. 8-17, 2002.

[27] I. F. F. Benzie and Y. T. Szeto, "Total antioxidant capacity of teas by the ferric reducing/antioxidant power assay," Journal of Agricultural and Food Chemistry, vol. 47, no. 2, pp. 633-636, 1999.

[28] M. H. Gordon, "The mechanism of antioxidant action invitro," in Food Antioxidants, B. J. F. Hudson, Ed., pp. 1-18, Elsevier Applied Science, London, UK, 1990.

[29] P. D. Duh, P. C. Du, and G. C. Yen, "Action of methanolic extract of mung bean hulls as inhibitors of lipid peroxidation and non-lipid oxidative damage," Food and Chemical Toxicology, vol. 37, no. 11, pp. 1055-1061, 1999.

[30] C. A. Rice-Evans, N. J. Miller, and G. Paganga, "Antioxidant properties of phenolic compounds," Trends in Plant Science, vol. 4, pp. 304-309, 1997. 


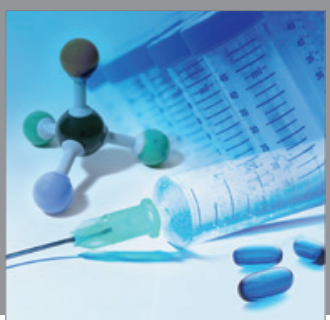

International Journal of

Medicinal Chemistry

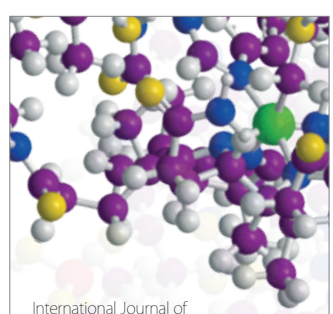

Carbohydrate Chemistry

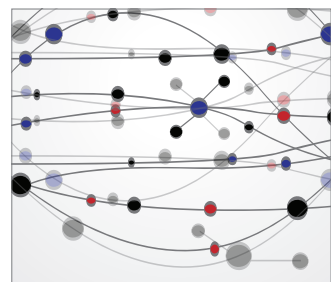

The Scientific World Journal
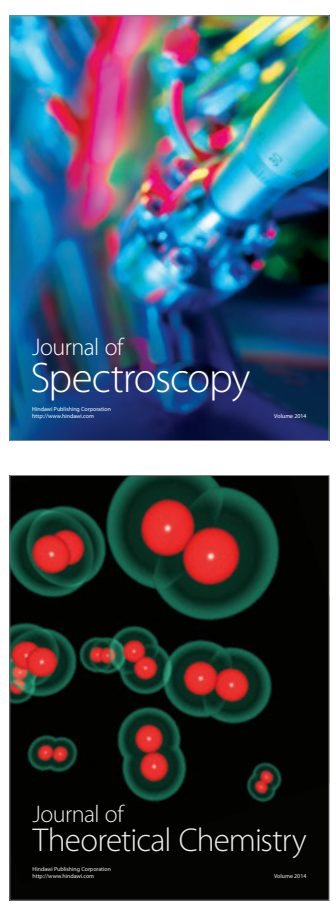
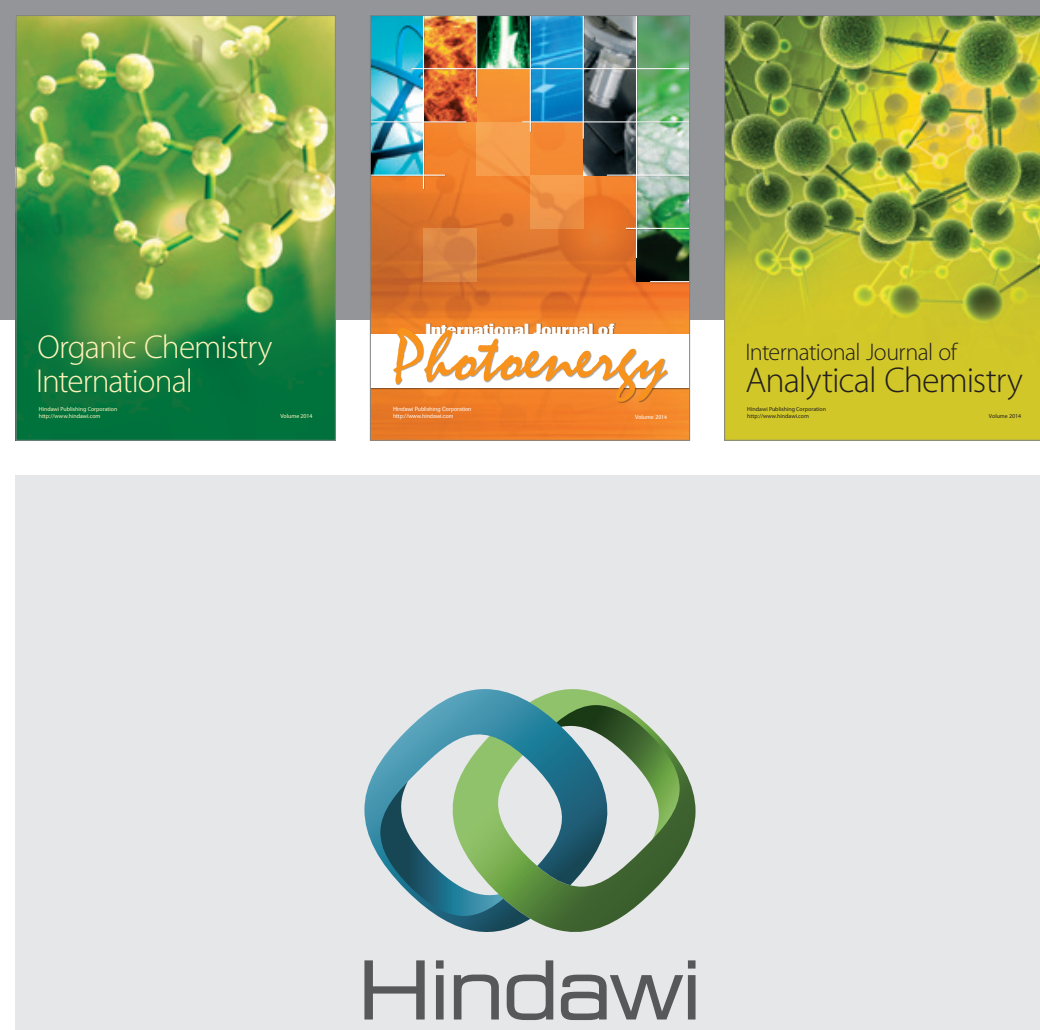

Submit your manuscripts at

http://www.hindawi.com
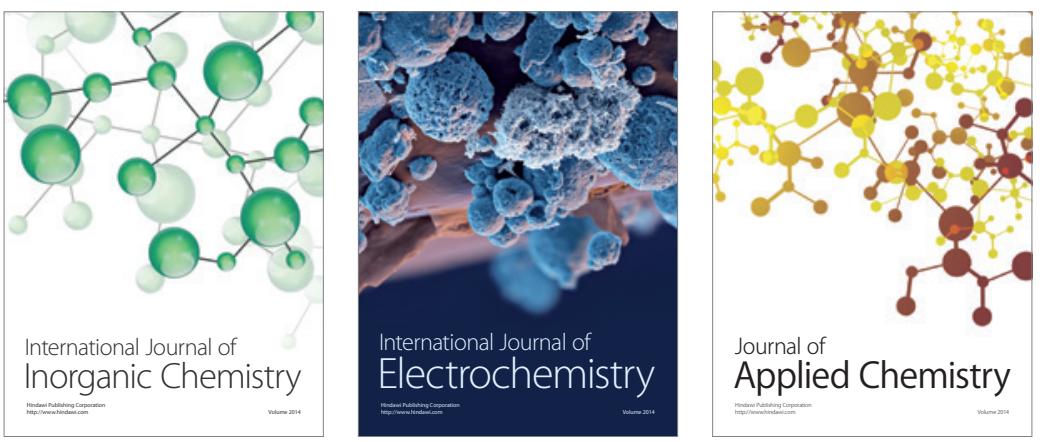

Journal of

Applied Chemistry
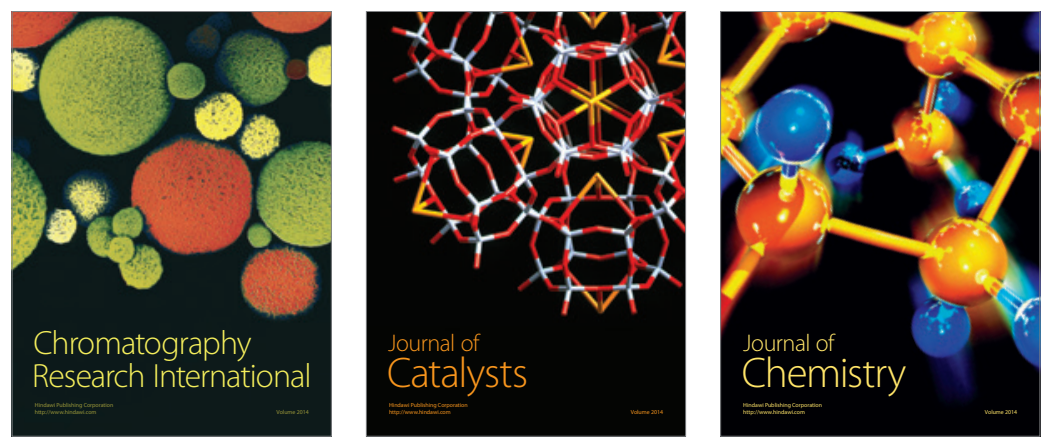
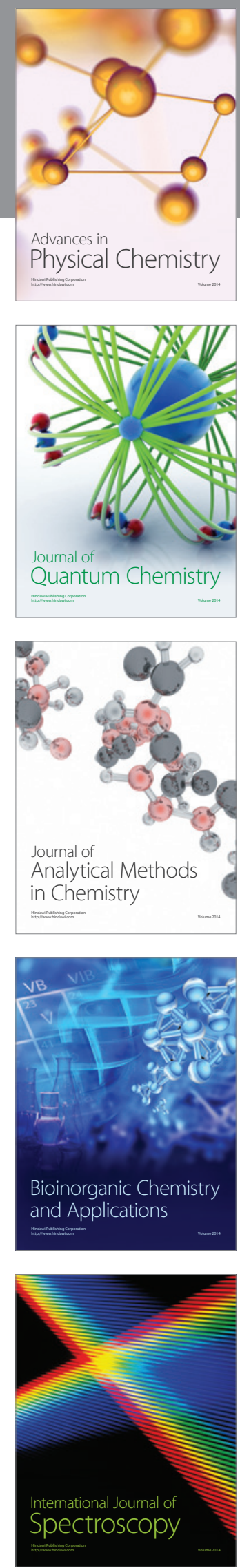